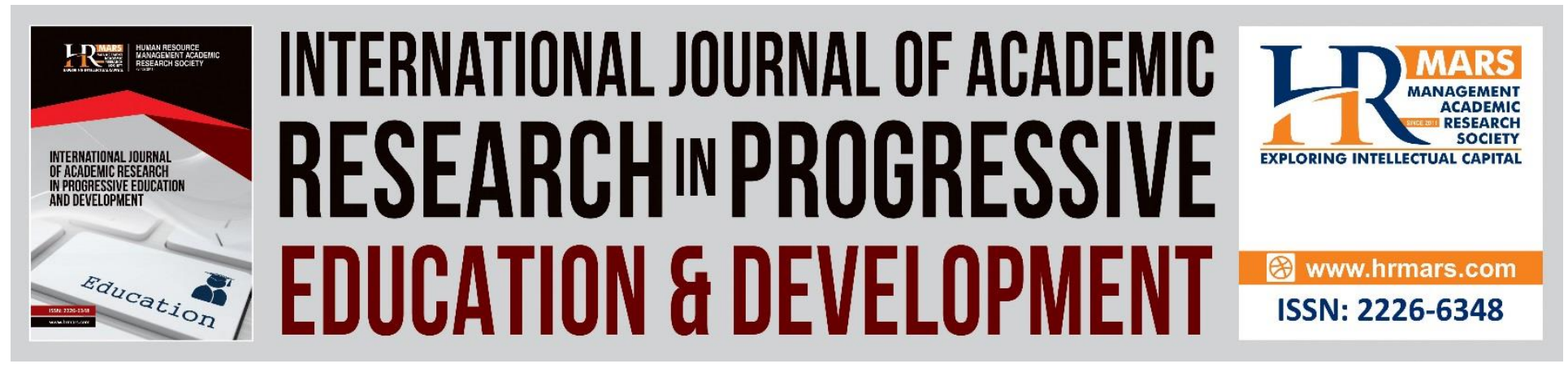

\title{
Students' Satisfaction on the Design of Kawaii Style Pedagogical Agent in the Virtual Learning Environment
}

Kaliyamah Raman, Ahmad Nizam Othman, Muhammad Zaffwan Idris, Vicneas Muniady

To Link this Article: http://dx.doi.org/10.6007/IJARPED/v10-i2/9592

DOI:10.6007/IJARPED/v10-i2/9592

Received: 09 February 2021, Revised: 12 March 2021, Accepted: 27 March 2021

Published Online: 21 April 2021

In-Text Citation: (Kaliyamah et al., 2021)

To Cite this Article: Kaliyamah, R., Ahmad Nizam, O., Muhammad Zaffwan, I., \& Vicneas, M. (2021). Students' Satisfaction on the Design of Kawaii Style Pedagogical Agent in the Virtual Learning Environment.

International Journal of Academic Research in Progressive Education and Development, 10(2), $134-149$.

Copyright: (C) 2021 The Author(s)

Published by Human Resource Management Academic Research Society (www.hrmars.com)

This article is published under the Creative Commons Attribution (CC BY 4.0) license. Anyone may reproduce, distribute, translate and create derivative works of this article (for both commercial and non-commercial purposes), subject to full attribution to the original publication and authors. The full terms of this license may be seen

at: http://creativecommons.org/licences/by/4.0/legalcode

Vol. 10(2) 2021, Pg. 134 - 149

http://hrmars.com/index.php/pages/detail/IJARPED

JOURNAL HOMEPAGE

Full Terms \& Conditions of access and use can be found at http://hrmars.com/index.php/pages/detail/publication-ethics 


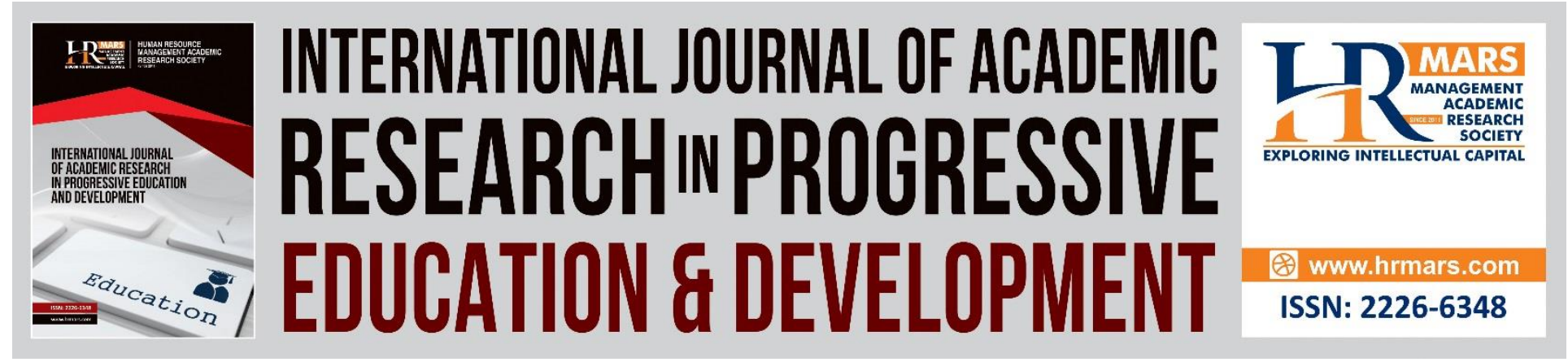

\title{
Students' Satisfaction on the Design of Kawaii Style Pedagogical Agent in the Virtual Learning Environment
}

\author{
Kaliyamah Raman ${ }^{1}$, Ahmad Nizam Othman ${ }^{1}$, Muhammad Zaffwan \\ Idris $^{1}$, Vicneas Muniady ${ }^{2}$
}

${ }^{1}$ Faculty of Art, Computing and Creative Industry, Universiti Pendidikan Sultan Idris, 35900 Tanjong Malim, Perak, Malaysia, ${ }^{2}$ Department of Information and Communication Technology, Politeknik Sultan Azlan Shah, 35950 Behrang Steysen, Perak, Malaysia

Email: logesri02@gmail.com

\begin{abstract}
A pedagogical agent is an on-screen virtual character that is used to serve instructional purposes in virtual learning environment (VLE). Of late, research about pedagogical agents has received increasing interest among researchers, but still there is little research on the facial appearance of animated pedagogical agent. Facial design of pedagogical agent is a key method to achieve believability among students. Pedagogical agent with more ideal facial design has greater motivational impact. Notably, a "cute" looking face is very essential as audience identifies with it the most. The term "cute" reminds one of the famous Japanese cultural term which is known as kawaii. Hence, this study aimed to develop kawaii design of pedagogical agent and look at its effect on students' satisfaction in VLE. Successive Approximation Model (SAM) is the basis for design and development of the pedagogical agents and VLE. A set of Post-Study System Usability Questionnaire (PSSUQ) was used to obtain feedback from students after the completion of learning process with the kawaii design of pedagogical agent in VLE. Overall, it can be concluded that the level of acceptance and satisfaction of students towards the kawaii design of pedagogical agent in VLE is good and positive.
\end{abstract}

Keywords: Cute, Kawaii, Pedagogical Agent, PSSUQ, Usability Study, Virtual Learning Environment

\section{Introduction}

Pedagogical agents are animated virtual characters that play human instructional roles in an educational environment (Saadatzi et al., 2017; Vicneas and Zamzuri, 2020). Hence, pedagogical agents reside within the digital space of Virtual Learning Environment (VLE) to facilitate students' engagement in the learning process (Hong, Chen and Lan, 2014; Liew, Zin and Sahari, 2017; 
Vicneas, Zamzuri and Kaliyamah, 2018). In recent years, pedagogical agents have been gaining influence in education as a tool to enhance teaching and learning processes (Veletsianos, 2010; Vicneas and Zamzuri, 2020). In an educational environment, pedagogical agents play a role as lecturer to facilitate students throughout the learning process (Schroeder and Gotch, 2015; Terzidou and Tsiatsos, 2014). With such role, pedagogical agent assists students (Carlotto and Jaques, 2016) to meet their learning needs and guides them throughout the learning process (Van der Meij, Van der Meij and Harmsen, 2015). Moreover, pedagogical agent is capable of aiding learning process by delivering learning materials and supporting cognitive tasks through its flexibility, support, and guidance (Clarebout and Elen, 2007). Consequently, pedagogical agent provides social enrichment in students' learning experience (Gulz, 2005). The literature showed that learning with pedagogical agent began to emerge as part of interactive VLE for more than a decade. Pedagogical agents play different roles in an educational environment including instructor, guider, collaboration assistant, motivator, expert, mentor, facilitator, and learning companions (Martha and Santoso, 2019; Vicneas and Zamzuri, 2020).

When an appealing pedagogical agent is presented in VLE, students are capable to practice student-centred learning and they would get emotionally connected to the agent (Dinçer and Doğanay, 2017). Thus, a strong bond formed between students and a pedagogical agent that is appealing to them. Consequently, students feel comfort and joy in interacting with this pedagogical agent. In this sense, students will enjoy their own learning and they will be more enthusiastic to learn the presented material (Dinçer and Doğanay, 2017). In such way, students' academic success and their performance can be enhanced significantly (Hong et al. 2014). Obviously, the usage of pedagogical agent in VLE is a great way to promote students' interest in learning content and their overall learning engagement (Park, 2018).

Consequently, the visual appearance is the most important element to consider first in the design of pedagogical agent. Usually, the visual appearance of pedagogical agent is designed based on the role it plays and little consideration is given on its impact in the learning process. However, it is still unclear on which features of a pedagogical agent contributes to an enhancement of motivation in learning among students. Therefore, this study will focus on the design of the pedagogical agents. With the advancement of human-computer interaction technology, it is possible to create pedagogical agent that looks more like a human (Martha and Santoso, 2019). Often, the design of pedagogical agent represents in digital forms which are called as twodimensional (2D) or three-dimensional (3D). Generally, pedagogical agent in the form of 3D resembles actual human with high realistic features (Vicneas and Zamzuri, 2020; Vicneas and Zamzuri, 2019; Walker, 2009). However, such pedagogical agents can cause discomfort, uneasiness, and anxiety among the viewers (Vicneas and Zamzuri, 2020; Vicneas and Zamzuri, 2019). Instead, 2D pedagogical agents can reflect a human with attractive appearance that provides a high level of comfort to the viewers (Walker, 2009). Specifically, Vicneas and Ahmad Zamzuri (2020) found that agents designed in 2D designs fall at high affective state. With that as a basis, pedagogical agent for the present research will be designed in the form of 2D.

It is believed that rich and interesting facial look of pedagogical agent has a powerful ability to make learning more fun. The first look at facial appearance is able to stimulate affective responses among people (Miesler, Leder and Herrmann, 2011). Notably, a "cute" looking face is very essential as audience identifies with it the most. The term "cute" in the context of a famous 
Japanese term can be associated with the local Japanese word called kawaii. Most popular word in Japan, kawaii in Japanese means cute in English (Kaliyamah, Nizam, Zaffwan and Vicneas, 2021; Nittono, Fukushima, Yano and Moriya, 2012; Takamatsu, 2018). Besides carrying the semantic meaning of an adorable look, kawaii also emphasises on the qualities of being sweet, adorable, innocent, and vulnerable in the physical appearances (Wong, 2017). Cuteness is a powerful motivational force that induces states of readiness to engage in social affiliation (Takamatsu, 2018). The cuteness as exemplified in kawaii style is related to human sociality that motivates people to interact socially with the given character by priming affiliative, friendly tendencies and imbuing mental states in the entity (Nittono, 2016).

Kawaii prevailed in inanimate objects such as desserts, fashion accessories, home decorations as well as baby animals and cartoon characters (Borgi et al. 2014; Nittono and Ihara, 2017). The world of kawaii design had set foot outside of Japan and influenced world-wide consumer cultural phenomenon through the production of various products with kawaii aesthetics (Granot, Alejandro and Russell, 2014; Yano, 2013). Besides that, consumer brands such as Mini, Motorola and Volkswagen have embraced 'cute' as an aesthetic design and successfully produced a variety of products that received great response from people around the world (Granot et al. 2014). Furthermore, kawaii has made a large impact around the world, especially in entertainment, video games, books, comics, fashion, commercial animation, and movies (Cheok and Fernando, 2012). Animated movies and video games create cute creature designs to appeal to audiences and increase sales (Bray, 2016; Winkielman, McIntosh and Oberman, 2009). Commonly, kawaii characters are shaped with simple facial characteristics such as large and round heads, large eyes, small noses, small mouths, chubby bodies, and short limbs. The kawaii characters provide a sense of security, intimacy and connection with audience as demonstrated in the example of Pokemon Go's success (Allison, 2002). The character of Pokemon Go (Fig.1) trigger the pleasure centre of the brain of the players (Nittono et al., 2012). As a result, the game raked in $\$ 1.8$ billion in revenue for Nantic, which owns Nintendo, in just two years (Tassi, 2018). Therefore, the question that surfaces is will similar impact be observed in an educational environment if pedagogical agent is designed in kawaii style?

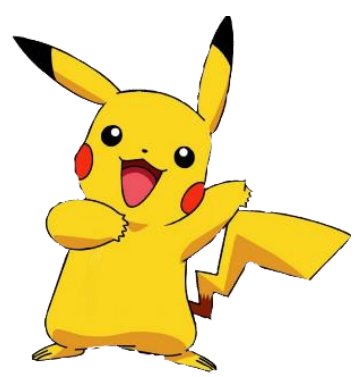

Figure 1: Pikachu (Pokémon GO, 2018)

Among the characteristics that facilitate the identification and fondness for a pedagogical agent comes from the attractiveness of pedagogical agent that is formed from its' physical resemblance including gender, age, and race. Hence, a female, young, attractive, and cool design of pedagogical agent is appropriate solution to develop an appealing agent for education purpose (Van der Meij et al. 2015). Such a design may benefit both male and female students equally (Plant et al., 2009). From the point of view of kawaii, it is often associated with girls and women 
(Macpherson and Jane, 2018; Nittono, 2016). This is in accordance with the cuteness appearance that appeals more to female than male in connection with the identification of feminine natural characteristics such as small, beautiful, and desirable (Granot et al., 2014). In other words, female character can provide higher ratings of cuteness than male (Nittono et al., 2012). Conversely, students are more influenced by pedagogical agents that are like themselves (Baylor, 2011). On the other hand, learning companion can be portrayed through the image of a youth in her 20s (Tien and Kamisah, 2010). Young Pedagogical agents uphold better outcomes (Johnson, Didonato and Reisslein, 2013). This is due to the excitement experienced by students when teaching is accompanied by learning companion (Tien and Kamisah, 2010). Besides, ethnic selection is an especially important factor too in the design of a pedagogical agent. Generally, students are fond to choose pedagogical agent that match their ethnicity (Kim and Wei, 2011; Liew, Su-Mae and Jayothisa, 2013). Moreover, students achieve higher in academic score and affective measures when they learn with pedagogical agent of the same ethnicity (Veletsianos, 2010). Hence, kawaii design of pedagogical agent was developed with VLE in which female pedagogical agent that localize Malaysian's young Malay girl was designed for the purpose of this research. This study aims to develop kawaii design pedagogical agent and VLE, and thereafter measure students' perceived satisfaction on the VLE. Lastly, the VLE was evaluated using Post-Study System Usability Questionnaire (PSSUQ).

\section{Design and Development}

There are many instructional design models that can be used to develop an instructional design such as ADDIE (analyse, design, develop, implement and evaluate) model SAM model (Successive Approximation Model), Dick and Carey model, Agile model, Kemp's instructional design model and so on. The selection of appropriate instructional design model is very important to achieve the main objectives of the instructional design. Specifically, the SAM model (Allen, 2012) was selected for the purpose of this study. SAM model (figure 2) focuses on speed, flexibility, and collaboration to generate an effective and efficient e-learning content (Jung, Kim, Lee and Shin, 2019). The SAM model is one of a relatively simple model that can be used in the field of education to develop good instructional materials. The SAM model provides a systematic approach for designing and developing a learning experience. The SAM model is a cyclical process that iterative. This means SAM consists of repetitive small steps which is technically known as iterations. Thus, SAM is an iterative prototyping model that works through small steps to ensure the work is proceeding on the right path (Allen, 2016). A revised step is required in each phase at least two to three times, and each cycle should be closer to ideal than the last one. This model contains three main phases namely evaluate or analysis phase, design phase and development phase. Each phase is related and interacting with one another. 


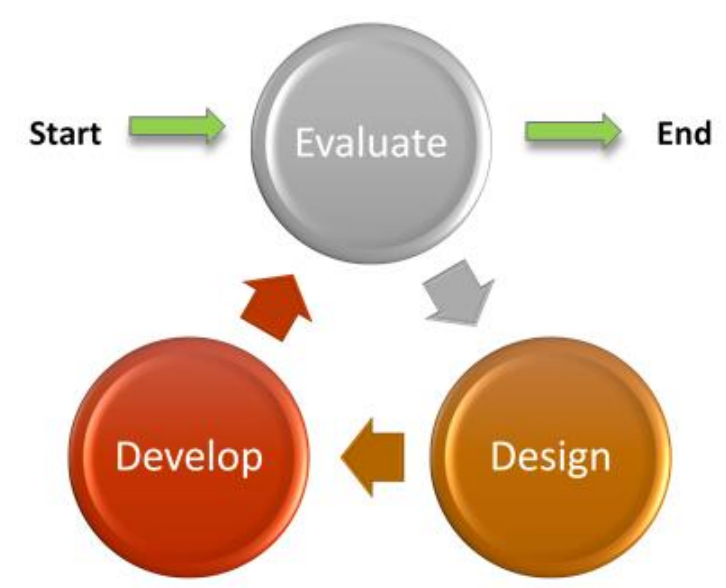

Figure 2: Successive Approximation Model

\section{a. Evaluation Phase}

The evaluation phase involves the gathering of important requirements or needs that are necessary in the creation of an educational content. First, the evaluation phase considers the delivery platform to clarify how the educational content will reach the target audience. For this purpose, Virtual Learning Environment (VLE) is chosen to deliver the learning content interactively. It is followed by the identification of the content area and targeted audience in the VLE. Interactive Multimedia Application (DEC40082) is one of the elective subjects for the fourth and fifth electrical engineering students in polytechnics. The complex structure of the theory of multimedia make teaching and learning of the subject more difficult. The VLE aims to introduce to the polytechnic students on the basic concepts relevant to Introduction to Multimedia in interactive way using pedagogical agent to replace the conventional learning styles. Therefore, the first chapter of this subject was chosen for this VLE. Besides that, the goal of designing the VLE have been defined so could produce a better quality of product. The main objective of the product is to implement animated pedagogical agent within the VLE to clearly deliver learning material to ensure students active engagement in the interactive learning process. In particular, the VLE is designed based on Keller's ARCS Model of Motivational Design (Keller, 1987) with the combination of multimedia elements such as text, graphic, audio, video, and animation.

Therefore, the VLE is presented in an interactive way by adding an attractive animated pedagogical agent to deliver the learning content clearly, interesting navigation control buttons and accessibility interface design of screens to catch the attention of students in ensuring they stay focus on the digital learning content. In the evaluation phase, the kind of technology and tools used to develop the educational content was decided upon as well. Correspondingly, the multimedia authorizing tools are chosen to develop all components of VLE. Adobe Illustrator was chosen to draw and design the pedagogical agent and the VLE. Then the adobe animate cc was chosen to animate the lips of pedagogical agent. Whereas the Adobe photoshop was selected to design the buttons for the VLE. The Audacity was selected to record the narration and edit audio. Notably, iteration process was also involved in the evaluation phase. In short, the delivery platform, content, objectives, target audience and software were identified in the first iteration. If necessary, any other constraints or relevant needs were determined in the second iteration. 


\section{b. Design Phase}

The design phase is a systematic and specific phase that describes a set of design strategies to achieve the goal of a project. The input of the design phase resulted from the evaluation phase. Here, the design phase involved the complete design of the Virtual Learning Environment (VLE). The content of the VLE was carefully selected in this design phase to ensure completeness and accuracy including pedagogical agent, graphic, video, animation, text, audio, and screen structure. Kawaii is very influential in global mainstream media (Lobato and Meese, 2014). The cuteness of kawaii widespread as a physical factor in characters used in media forms such as comics, cartoons and animations that specifically target younger audience. However, there is rising popularity and appreciation for the cuteness of kawaii that targets a broad age range as well. To reach students, pedagogical agent for the VLE will be designed to resemble kawaii style which means that it needs to be created in an interesting way that captures all aspects of cuteness. Besides, the notion of cute in kawaii can be derived from baby-likeness and it is intrinsically referred to female (Borgi et al., 2014). Hence, a female, young, attractive, and cool design of pedagogical agent is the appropriate solution to develop an appealing agent for educational purpose (Van der Meij et al. 2015). Such a design may benefit both male and female students equally (Plant et al., 2009). The pedagogical agent was designed based on the proposition on kawaii design as shown in Table 1.

Table 1: The Detail on Proportion for Kawaii Design of Pedagogical Agent

\begin{tabular}{ll}
\hline Features & Kawaii-style pedagogical agent \\
\hline Head & Large head relative to body size \\
Body & shrink the body than head \\
Forehead & Low forehead \\
Eyes & Bigger but smaller than KB eyes \\
Nose & Bigger than KB nose \\
Lips & Bigger than KB Lips \\
Cheeks & No chubby cheeks \& add pinkish tinge on the cheeks \\
Eyebrows & Raised \\
Chin & Wide chin \\
\hline
\end{tabular}

Besides, the design of the instructional content structure of the Virtual Learning Environment (VLE) was based on Keller's ARCS Model of Motivational Design (Keller, 1987). There are four main components in the ARCS model that play vital role in designing instructional materials namely attention, relevance, confidence, and satisfaction. All four components have great potential to positively stimulate motivation, engagement, and interaction in learning. In virtual learning environment, information delivered using multimedia elements such as text, graphic, audio, video, and animation offer students effective learning experience that match their learning style (Liew and Tan, 2016). The content with the support of multimedia elements presents an entirely new Virtual Learning Environment (VLE) for students. The integration among rich multimedia elements offers greater interactivity to students and consequently provides interesting learning experience (Sivadass et al., 2018). Therefore, the development of the VLE uses various types of multimedia elements to enhance content visualization and user interaction 
(Lau, Yen, Li and Wah, 2014). At this phase, storyboard also will be developed. The storyboard consists of nine screens together with dialogues of the pedagogical agent. The design process of the pedagogical agents and the VLE contained few design iterations which initially started off with quick rough sketch in the form of visual. Each iteration replaced in subsequent iterations to analyse the strength and limitations which replace them with better design. The lack of information also can be added along the iterations to come up with entirely new and superior design.

\section{c. Develop Phase}

Development phase is the process of producing the outcome that corresponds to specifications determined from the evaluate and design phase. The development phase followed right after the design phase. It also refers to the process of transferring all the planning and documents from the design phase to make them more practical. This development phase will be carried out with the help of multimedia authorising tools such as Adobe Animate CC, Adobe Photoshop and so on. It involved the production of animated pedagogical agent according to design specifications and it would be embedded with audio narrations according to scripts. In addition, to develop the kawaii design of pedagogical agent, iteration processes were completed three times until the final pedagogical agent was completed. In the first iteration, technical specifications which were determined in the design phase were implemented. The second iteration is an improved version of its previous iteration and it has been sent to experts to validate it. The experts validated the products and offer feedback regarding what needed to change or could be changed. The third iteration was the final iteration for the present designs where changes were made based on the feedbacks from experts as shown below (Figure 3). Now, the developed animated pedagogical agent is ready to be embedded implement in the VLE.

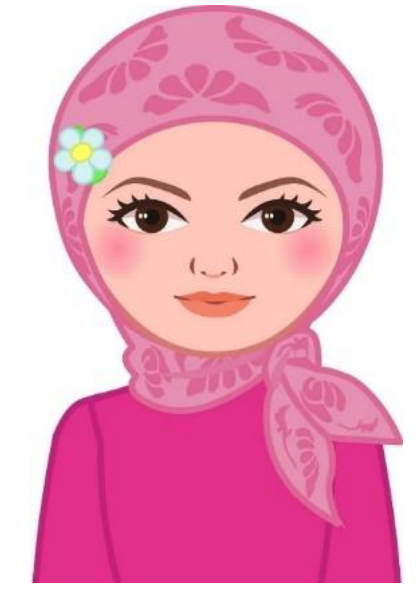

Figure 3: Kawaii-style pedagogical agent

Basically, interfaces of screen designs can be used as part of human-machine interaction. There are multiple interfaces of screen designs with the composition of the various elements and contents that are developed for the Virtual Learning Environment (VLE) as sketched in the design phase. These are inclusive of home screen, learning outcomes screen, learning content screen, interval support screen, quiz screen, question screen, feedback screen, reward screen and review screen. After the development of the interfaces of screen designs using authorizing software, the 
screens were arranged logically and linked to each other. Each of the screen was embedded with the designed kawaii-style pedagogical agent. The final products of the VLE were sent to expert for validation before they were used for research purpose. Consequently, The VLE was accepted by the experts. Thus, the following iteration was not carried out for the development of interfaces of screen designs of the VLE.

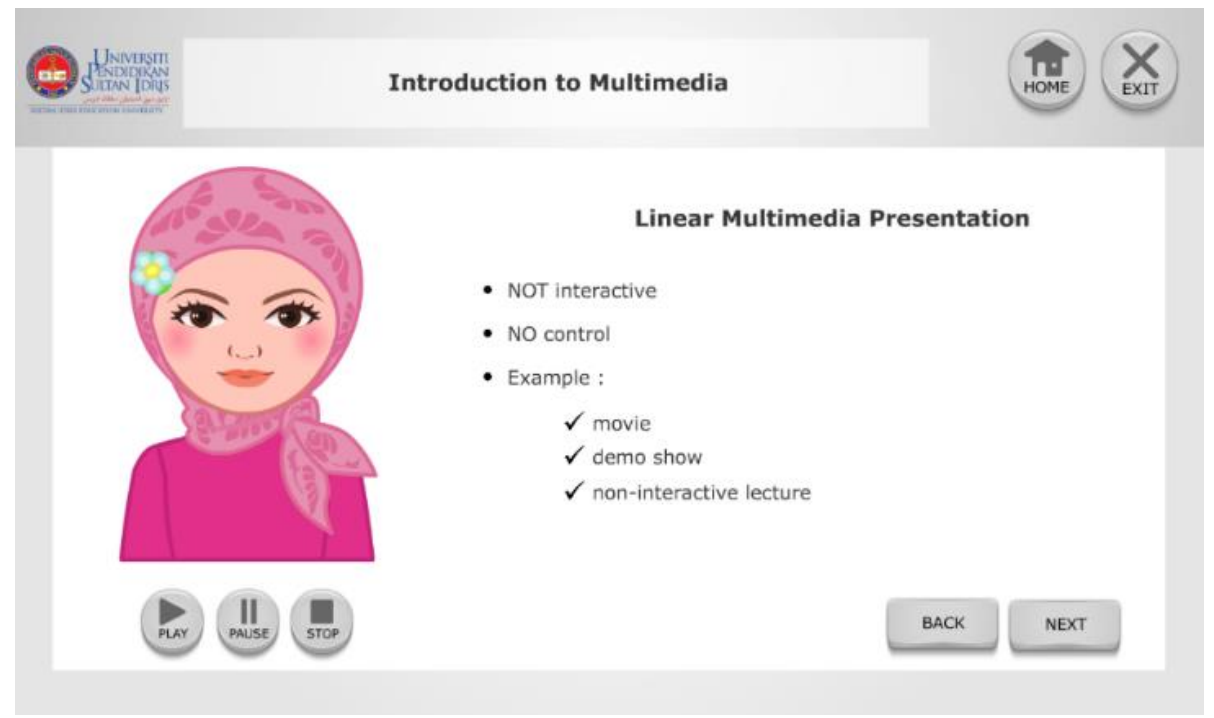

Figure 4: Learning content screen of kawaii-style pedagogical agent

\section{Methodology}

The aim of this study is to develop kawaii design pedagogical agent together with Virtual Learning Environment (VLE) and then to evaluate user's experience towards it. For that for Interactive Multimedia Application (DEC40082) subject was chosen. VLE was developed based on first chapter of chosen subject.

\section{a. Samples}

The study sample consisted of 39 polytechnic students from Politeknik Sultan Azlan Shah with mean age 20.08 (SD =0.53). The students are fifth semester students who have enrolled in electrical engineering course. The sample consists of $84.6 \%$ male students and $15.4 \%$ female students from the same class.

\section{b. Instruments}

After the completion of development process, the Virtual Learning Environment (VLE) is evaluated using Post-Study System Usability Questionnaire (PSSUQ). PSSUQ questionnaire is suitable to use for research to measure user's usability and satisfaction (Lewis, 2002; Pellizzoni, de Avila e Silva and Falavigna, 2020). Usability is an important aspect to be measured to identify the quality of the VLE (Arijaya et al., 2020). The PSSUQ questionnaire has five aspects of variables with 21 items and uses a Likert scale that ranges from 1 (strongly disagree) to 7 (strongly agree). The five aspects of variables are including design or layout, functionality, ease of use, learnability, 
satisfaction, outcome or future use and errors or system reliability. Based on the Likert scale, higher scores signify better ratings in all the scores.

\section{c. Procedure}

The PSSUQ questionnaire was completed by 39 respondents who are polytechnic students. At first, the students have been given a general explanation about the VLE and instructions on answering the PSSUQ questionnaire. Thereafter, students went through the VLE for around 20 minutes. The PSSUQ questionnaire sets were distributed as soon as students completed using the VLE. Respondents took ten to fifteen minutes to answer all the items in the PSSUQ questionnaire.

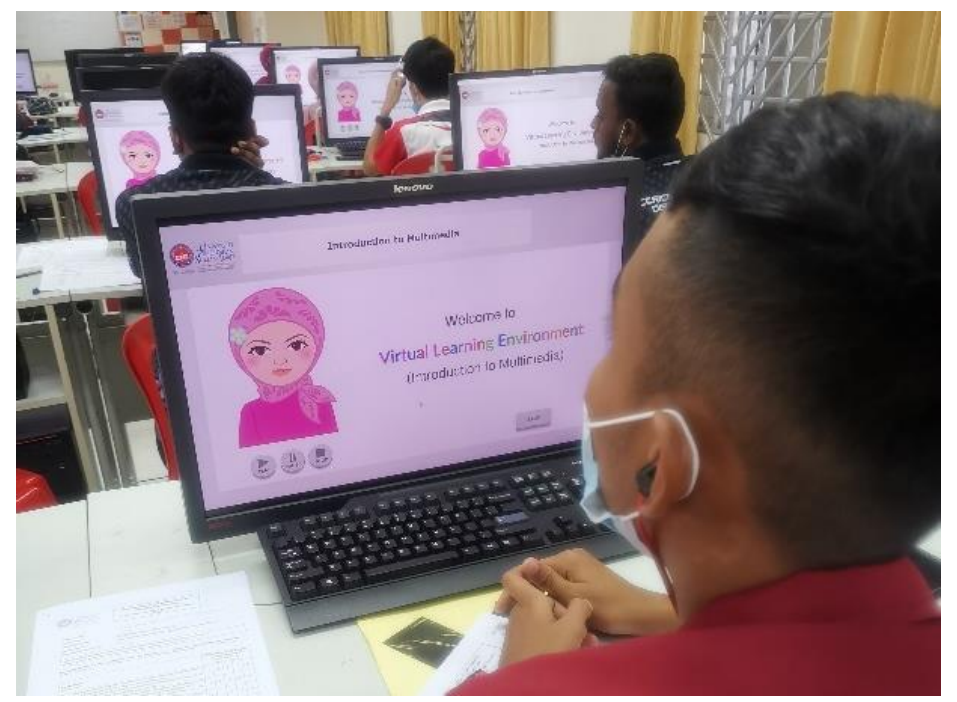

Figure 5: Usability testing with polytechnic students

\section{Results and Discussion}

The data obtained were analysed quantitatively using SPSS software. In general, the Cronbach's alpha value was calculated to identify the reliability of the VLE. The Cronbach's alpha value for the usability test and user satisfaction of the PSSUQ questionnaire of this study had high reliability measures which reached 0.96 for a total of 21 items. This value indicated the high reliability of the items in the PSSUQ questionnaire. Next, the data obtained from the PSSUQ questionnaire were processed by calculating the mean values and standard deviations values. Detailed analysis was done by looking at the mean value (M) and standard deviation (SD) for each of the seven aspects of student feedback.

\section{a. Design / Layout}

Aspect of design or layout is an overall view of the students on the design of VLE. Overall, students agreed that the VLE has good appeal, and they like to use it ( $M=5.0, S D=1.38$ ) and the organization of information on the VLE screens was clear $(M=5.4, S D=1.16)$. Students also agreed that the interface of the VLE was pleasant $(M=5.5, S D=1.21)$. 
DEVELOPMENT

Vol. 10, No. 2, 2021, E-ISSN: 2226-6348 @ 2021 HRMARS

\section{b. Functionality}

At the same time, the aspect of functionality represents the students' view on the overall function of the VLE. Through the evaluation of this aspect, students agreed that the VLE has all the functions and capabilities as they expect $(M=5.1, S D=1.26)$. Students felt that the information provided in the VLE was clear $(M=5.4, S D=1.21)$ and all the features in the VLE functions well $(M=5.9, S D=1.15)$.

\section{c. Ease of Use}

The aspect of ease of use explains how easy VLE can be used to achieve the learning outcomes with effectiveness and efficiency. For this aspect, the students agreed that the use of the VLE was simple $(M=5.8, S D=0.96)$, they can easily find the information needed $(M=5.5, S D=1.30)$ and the provided information was clear $(M=5.7, S D=1.22)$. Overall, the students accepted that the VLE is easy to use $(M=5.9, S D=1.09)$.

\section{d. Learnability}

On the other hand, the aspect of learnability describes the quality of the VLE that allows students to learn quickly and understand easily. Students felt it was easy to learn by using the VLE (M = $5.7, S D=0.97)$. They agreed that there was not too much information to read before using the $\operatorname{VLE}(M=5.1, S D=1.36)$ and the provided information was easy to understand $(M=5.7, S D=$ 1.13).

\section{e. Satisfaction}

The aspect of satisfaction refers to the users' pleasant feeling that they get after completing the VLE. Thereby, students felt comfortable using the VLE $(M=5.5, S D=1.23)$. Consequently, they enjoyed exploring the VLE $(M=5.6, S D=1.31)$. Overall, students were satisfied with the VLE (M $=5.4, \mathrm{SD}=1.31$.

\section{f. Outcome / Future Use}

The aspect of outcome or future use is about the impact of VLE on students in the future. Thus, students believed that they could become productive quickly using the VLE $(M=5.3, S D=1.21)$ and the VLE is able to convince them on improving their skills $(M=5.3, S D=1.33)$. Moreover, students trusted that they would use the VLE regularly $(M=5.2, S D=1.37)$.

\section{g. Errors / System Reliability}

In addition, the aspect of errors or system reliability represents the performance of the VLE that is capable to perform correctly without any error. Students believed that they could recover easily and quickly whenever they made a mistake using the VLE ( $M=5.4, S D=1.16)$. However, students gave neutral response to the statement that explains the VLE capable to give error messages that clearly told them how to fix the problem $(M=4.8, S D=1.68)$.

In sum, it can be seen clearly that all the items in the PSSUQ questionnaire achieved higher mean values which signifying better ratings in overall. Hence, the outcomes from the usability test and user satisfaction of the PSSUQ questionnaire indicates that overall, the students were satisfied with the VLE. 


\section{Conclusion}

Pedagogical agent is a lifelike character that is presented on computer screen to support learning process. The idea of using animated pedagogical agent in an education environment is expanding widely. Pedagogical agent functioned as an instructor and able to assist students throughout the learning process. Eventually, the role played by animated pedagogical agents in the Virtual Learning Environment (VLE) is capable to capture students' attention and their interest and consequently engage them to participate actively throughout the interactive learning process. According to the usability study, it has been found that students are very satisfied with the developed VLE. Ultimately, the role played by kawaii design animated pedagogical agent in the VLE capable to draw students' attention and their interest and consequently engage them participate actively throughout the interactive learning process. Hence, in future, instructional designers could modify the VLE to deliver learning content for other courses as well by using the kawaii design pedagogical agent. A future study investigating baby schema design in pedagogical agent would be very interesting.

\section{Acknowledgment}

Kaliyamah Raman acknowledges the Ministry of Higher Education of Malaysia for awarding the HLP scholarship (Hadiah Latihan Persekutuan) to pursue this research.

\section{References}

Allen, M. (2012). Leaving ADDIE for SAM: An agile model for developing the best learning experiences. Alexandria, VA: ASTD Press.

Allen, M. W. (2016). Michael Allen's guide to e-learning: Building interactive, fun, and effective learning programs for any company. John Wiley \& Sons.

Allison, A. (2002). The Cultural Politics of Pokemon Capitalism. Media in Transition, (2), 178-200. Retrieved from https://cmsw.mit.edu/mit2/Abstracts/AnneAllison.pdf

Arijaya, I. G. N. P., Pradnyana, I. M. A., Wirawan, I. M. A., Suwendra, I. G. P., Nugraha, I. W., and Suparta, I. N. (2020). Usability testing in tourism object management system in 3rd International Conference on Innovative Research Across Disciplines (ICIRAD 2019), 139-144.

Baylor, A. L. (2011). The design of motivational agents and avatars. Educational Technology Research and Development, 59(2), 291-300. https://doi.org/10.1007/s11423-011-9196-3

Borgi, M., Cogliati-Dezza, I., Brelsford, V., Meints, K., \& Cirulli, F. (2014). Baby schema in human and animal faces induces cuteness perception and gaze allocation in children. Frontiers in Psychology. https://doi.org/10.3389/fpsyg.2014.00411

Bray, N. (2016). Behavioural neuroscience: on the defensive. Nat. Rev. Neurosci. 17, 463. doi: 10.1038/nrn.2016.88

Carlotto, T., \& Jaques, P. A. (2016). The effects of animated pedagogical agents in an English-asa-foreign-language learning environment. International Journal of Human Computer Studies, 95, 15-26. doi:10.1016/j.ijhcs.2016.06.001

Cheok, A. D., \& Fernando, O. N. N. (2012). Kawaii/Cute interactive media. Universal Access in the Information Society, 11(3), 295-309. https://doi.org/10.1007/s10209-011-0249-5

Clarebout, G., \& Elen, J. (2007). In search of pedagogical agents' modality and dialogue effects in open learning environments. E-Journal of Instructional Science and Technology, 10(1). 
INTERNATIONAL JOURNAL OF ACADEMIC RESEARCH IN PROGRESSIVE EDUCATION AND

DEVELOPMENT

Vol. 10, No. 2, 2021, E-ISSN: 2226-6348 @ 2021 HRMARS

Retrieved from http://eric.ed.gov/?id=EJ846724

Dinçer, S., \& Doğanay, A. (2017). The effects of multiple-pedagogical agents on learners' academic success, motivation, and cognitive load. Computers and Education, 111, 74-100. https://doi.org/10.1016/j.compedu.2017.04.005

Granot, E., Alejandro, T. B., \& Russell, L. T. M. (2014). A socio-marketing analysis of the concept of cute and its consumer culture implications. Journal of Consumer Culture, 14(1), 66-87. https://doi.org/10.1177/1469540513485274

Gulz, A. (2005). Social enrichment by virtual characters - Differential benefits. Journal of Computer Assisted Learning, 21(6), 405-418. https://doi.org/10.1111/j.13652729.2005.00147.x

Hong, Z.-W., Chen, Y.-L., \& Lan, C.-H. (2014). A courseware to script animated pedagogical agents in instructional material for elementary students in English education. Computer Assisted Language Learning, 27(5), 379-394. http://doi.org/10.1080/09588221.2012.733712

Johnson, A. M., Didonato, M. D., \& Reisslein, M. (2013). Animated agents in K-12 engineering outreach: Preferred agent characteristics across age levels. Computers in Human Behavior, 29(4), 1807-1815. https://doi.org/10.1016/j.chb.2013.02.023

Jung, H., Kim, Y. R., Lee, H., \& Shin, Y. (2019). Advanced instructional design for successive Elearning: Based on the successive approximation model (SAM). International Journal on ELearning: Corporate, Government, Healthcare, and Higher Education, 18(2), 191-204. Retrieved from https://www.researchgate.net/publication/331829482_Advanced_Instructional_Design_f or_Successive_E-Learning_Based_on_the_Successive_Approximation_Model_SAM

Kaliyamah, R., Nizam, A. O., Zaffwan, M. I., \& Vicneas, M. (2021). Kawaii-style pedagogical agents designs in virtual learning environment: a research conceptual framework. International Journal of Academic Research in Progressive Education and Development, 10(1), 154-170. doi:10.6007/IJARPED/v10-i1/8489

Keller, J. M. (1987). Development and use of the ARCS model of motivational design. Journal of Instructional Development, 10(1932), 2-10.

Kim, Y., \& Wei, Q. (2011). The impact of learner attributes and learner choice in an agent-based environment. Computers \& Education, 56(2), 505-514. Retrieved from http://drmokhberi.ir/wp-content/uploads/2013/09/1-s2.0-S0360131510002794-main.pdf

Lau, R. W. H., Yen, N. Y., Li, F., \& Wah, B. (2014, March). Recent development in multimedia elearning technologies. World Wide Web. https://doi.org/10.1007/s11280-013-0206-8

Lewis, J. R. (2002). Psychometric evaluation of the PSSUQ using data from five years of usability studies. International Journal of Human-Computer Interaction. 14(3-4), 463-488. doi: 10.1080/10447318.2002.9669130

Liew, T. W., Su-Mae, T., \& Jayothisa, C. (2013). The effects of peer-like and expert-like pedagogical agents on learners' agent perceptions, task-related attitudes, and learning achievement. Journal of Educational Technology \& Society, 16(4), 275. Retrieved from https://pdfs.semanticscholar.org/918f/fcdb3b1d807714b2f0621752b9a14447c193.pdf

Liew, T. W., \& Tan, S. M. (2016). The effects of positive and negative mood on cognition and motivation in multimedia learning environment. Journal of Educational Technology \& Society, 19(2), 104-115. Retrieved from 
Vol. 10, No. 2, 2021, E-ISSN: 2226-6348 @ 2021 HRMARS

https://www.jstor.org/stable/jeductechsoci.19.2.104

Liew, T. W., Mat Zin, N. A., Sahari, N., \& Tan, S. M. (2016). The effects of a pedagogical agent's smiling expression on the learner's emotions and motivation in a virtual learning environment. International Review of Research in Open and Distance Learning, 17(5), 248266. https://doi.org/10.19173/irrodl.v17i5.2350

Liew, T. W., Mat Zin, N. A., \& Sahari, N. (2017). Exploring the affective, motivational and cognitive effects of pedagogical agent enthusiasm in a multimedia learning environment. HumanCentric Computing and Information Sciences, 7(1). https://doi.org/10.1186/s13673-0170089-2

Lobato, R., \& Meese, J. (2014). Kittens All the Way Down: Cute in Context. A Journal of Media and Culture, $17(2)$. Retrieved from https://pdfs.semanticscholar.org/7000/172a7fde9d3d561b9e82566e975c7530ce06.pdf?_ ga $=2.204961040 .1092994524 .1578476508-1353836849.1569467420$

Macpherson, I., \& Jane, B. T. (2018). Softening Power: Cuteness as Organizational Communication Strategy in Japan and the West. Journal of International and Advanced Japanese Studies, 10, 39-55. https://doi.org/10.15068/00151651

Martha, A. S. D., \& Santoso, H. B. (2019). The design and impact of the pedagogical agent: A systematic literature review. Journal of Educators Online 16(1). https://doi.org/10.9743/jeo.2019.16.1.8

Miesler, L., Leder, H., \& Herrmann, A. (2011). Isn't it cute: An evolutionary perspective of babyschema effects in visual product designs. International Journal of Design, 5(3), 17-30. Retrieved from http://ppcms.univie.ac.at/fileadmin/usermounts/lederh7/2011/MieslerLederHerrmann20 11.pdf

Nittono, H., Fukushima, M., Yano, A., \& Moriya, H. (2012). The Power of Kawaii: Viewing Cute Images Promotes a Careful Behavior and Narrows Attentional Focus. PLoS ONE, 7(9). https://doi.org/10.1371/journal.pone.0046362

Nittono, H. (2016). The two-layer model of 'kawaii': A behavioural science framework for understanding kawaii and cuteness. East Asian Journal of Popular Culture, 2(1), 79-95. https://doi.org/10.1386/eapc.2.1.79_1

Nittono, H., \& Ihara, N. (2017). Psychophysiological Responses to Kawaii Pictures With or Without Baby Schema. SAGE Open, 7(2). https://doi.org/10.1177/2158244017709321

Park, S. (2018). Virtual Pedagogical Agents for English Language Teaching and Learning. In The TESOL Encyclopedia of English Language Teaching (pp. 1-9). https://doi.org/10.1002/9781118784235.eelt0912

Pellizzoni, L., De Avila e Silva, S., \& Falavigna, A. (2020). Multilanguage health record database focused on the active follow-up of patients and adaptable for patient-reported outcomes and clinical research design. International Journal of Medical Informatics. vol.135. doi: 10.1016/j.ijmedinf.2019.104065.

Plant, E. A., Baylor, A. L., Doerr, C. E., \& Rosenberg-Kima, R. B. (2009). Changing middle-school students' attitudes and performance regarding engineering with computer-based social models. Computers \& Education, 53(2), 209-215. Retrieved from http://www.rinatrosenbergkima.com/PDF/PlantAll_CAE_2009.pdf 
Pokémon GO [Image]. (2018). Catch Pokémon in the Real World with Pokémon GO! Retrieved from https://www.pikpng.com/pngvi/iohhimw_picachu-sticker-pokemon-pikachu-clipart/

Saadatzi, M. N., Pennington, R. C., Welch, K. C., Graham, J. H., \& Scott, R. E. (2017). The use of an autonomous pedagogical agent and automatic speech recognition for teaching sight words to students with autism spectrum disorder. Journal of Special Education Technology, 32(3), 173-183.

Schroeder, N. L., \& Gotch, C. M. (2015). Persisting issues in pedagogical agent research. Journal of Educational Computing Research, 53(2), 183-204. https://doi.org/10.1177/0735633115597625

Sivadass, T., Chareen, S. C., Faiqa, A. N., \& Nabilah, N. B. (2018). Conceptual Approach of Developing a Courseware to Educate Schoolchildren in Raising Resilence Towards Flood Disaster. In: Knowledge Management International Conference (KMICe) 2018. Retrieved from https://pdfs.semanticscholar.org/252a/afd3436ec75571ecf32fd81cdf3c66edd009.pdf?_ga $=2.242711170 .1092994524 .1578476508-1353836849.1569467420$

Takamatsu, R. (2018). Measuring Affective Responses to Cuteness and Japanese kawaii as a Multidimensional Construct. Current Psychology, 1-13. https://doi.org/10.1007/s12144018-9836-4

Tassi, P. (2018). 'Pokémon GO' Has Made \$1.8 Billion As It Turns Two Years Old. 'Pokémon GO' Has Made $\$ 1.8$ Billion As It Turns Two Years Old. Retrieved from https://www.forbes.com/sites/insertcoin/2018/07/09/pokemon-go-has-made-1-8-billionas-it-turns-two-years-old/\#65cad52f4655

Terzidou, T., \& Tsiatsos, T. (2014). The impact of pedagogical agents in 3D collaborative serious games. In 2014 IEEE Global Engineering Education Conference (EDUCON), (pp. 1175-1182). https://doi.org /10.1109/EDUCON.2014.7130487

Tien, L. T., \& Kamisah, O. (2010). Pedagogical agents in interactive multimedia modules: Issues of variability. Procedia - Social and Behavioral Sciences, 7(2), 605-612. http://doi.org/10.1016/j.sbspro.2010.10.082

Van der Meij, H., Van der Meij, J., \& Harmsen, R. (2015). Animated pedagogical agents effects on enhancing student motivation and learning in a science inquiry learning environment. Educational Technology Research and Development, 381-403. http://doi.org/10.1007/s11423-015-9378-5

Veletsianos, G. (2010). Contextually relevant pedagogical agents: Visual appearance, stereotypes, and first impressions and their impact on learning. Computers and Education, 55(2), 576-585. https://doi.org/10.1016/j.compedu.2010.02.019

Vicneas, M., Zamzuri, A. M. A., \& Kaliyamah, R. (2018). Development and Evaluation of 2D Virtual Agent Multimedia Quiz App. Advanced Journal of Technical and Vocational Education, 2(4), 8-13. https://doi.org/10.26666/rmp.ajtve.2018.4.2

Vicneas, M., \& Zamzuri, A. M. A. (2019). Different realism designs of $2 d$ virtual agents and its arousal effect on students' emotions in learning. International Journal of Engineering and Advanced Technology, 9(1), 5149-5158. doi: 10.35940/ijeat.a1754.109119

Vicneas, M., \& Zamzuri, A. M. A. (2020). The effect of valence and arousal on virtual agent's designs in quiz based multimedia learning environment. International Journal of Instruction, 
INTERNATIONAL JOURNAL OF ACADEMIC RESEARCH IN PROGRESSIVE EDUCATION AND

DEVELOPMENT

Vol. 10, No. 2, 2021, E-ISSN: 2226-6348 @ 2021 HRMARS

13(4), 903-920. doi: 10.29333/iji.2020.13455a

Walker, S. J. (2009). A quick walk through Uncanny Valley. In A. Oddey \& C. White (Eds.), Modes of spectating (pp. 29-40). Bristol: Guntenberg Press.

Winkielman, P., Mclntosh, D. N., \& Oberman, L. (2009). Embodied and disembodied emotion processing: Learning from and about typical and autistic individuals. Emotion Review. https://doi.org/10.1177/1754073908100442

Wong, S. (2017). Yuru-kyara and Mascot Characters: Cute Aesthetics and the Empathic Effect of Kawaii in Japanese Commercials. Retrieved from https://www.researchgate.net/publication/328462785_Yuru-

kyara_and_Mascot_Characters_Cute_Aesthetics_and_the_Empathic_Effect_of_Kawaii_in_ Japanese_Commercials

Yano, C. R. (2013). Pink globalization: Hello Kitty's trek across the Pacific. Durham, NC: Duke University Press 